Gut, 1961, 2, 1

\title{
Mucosal tears at the oesophagogastric junction (the Mallory-Weiss syndrome)
}

\author{
MICHAEL ATKINSON 1 , M. B. BOTTRILL ${ }^{2}$, A. T. EDWARDS 4 , WINIFRED \\ M. MITCHELL ${ }^{2}$, B. GADSBY PEET ${ }^{3}$, \& R. E. WILLIAMS
}

From St. James's Hospital, Leeds, and Halifax General Hospital

SYNOPSIS This is a re-appraisal of the supposedly rare Mallory-Weiss syndrome in which 11 patients with mucosal tears at the oesophagogastric junction are described. The fact that these cases were collected from general hospitals within a short period suggests that the condition is more common than supposed and may account for a considerable proportion of the 20 to $25 \%$ of patients with upper gastrointestinal bleeding in whom no radiological abnormality can subsequently be found.

Of the 11 patients, eight presented with gastrointestinal bleeding, two with mediastinitis, and one without relevant symptoms. The classical history of antecedent vomiting before the bleeding was obtained in only four patients, its absence not excluding the diagnosis. The presence of a small hiatal hernia in four patients appeared to predispose to mucosal tears as did mucosal atrophy occurring with advancing age. Some experimental findings pertaining to the mechanism of the tears are presented.

In 1929, Mallory and Weiss described the syndrome which bears their name. Fifteen patients developed massive haematemesis after prolonged bouts of alcoholic debauch and in each case bloodless vomiting preceded the haematemesis. Post-mortem examinations of four of these patients revealed multiple mucosal fissures, $3-20 \mathrm{~mm}$. in length and 2-3 mm. in breadth, situated around the circumference of the cardia with their long axes in line with the oesophagus. Histological examination revealed that these ulcers extended into the muscularis and their floor consisted of fresh fibrin and polymorphonuclear leucocytes. The appearances suggested an acute rupture of the mucosa and experiments on a stomach in a cadaver showed that similar lesions could be produced by gastric distension when the oesophagus was occluded at the level of the diaphragm. They concluded that 'pressure changes in the stomach during a disturbed mechanism of vomiting and continuous regurgitation of gastric juice over the cardia' were the important predisposing factors. In 1932, the same authors reported a further six cases of this condition, two of which were

\footnotetext{
Present addresses:

${ }^{1}$ Department of Medicine, The University of Leeds, Leeds General Infirmary

${ }^{2}$ Department of Pathology, St. James's Hospital, Leeds

${ }^{3}$ Leeds General Infirmary

'Department of Pathology, Halifax General Hospital
}

fatal. Post-mortem examination of the first of these revealed a single fissured ulcer extending into the muscularis. The second patient died of mediastinitis after rupture of an ulcer into the mediastinum. In only six of the total of 21 cases described by Mallory and Weiss was a tear actually seen and in the remainder the diagnosis was made on the history alone.

Decker, Zamcheck, and Mallory in 1953 recorded 11 cases of the Mallory-Weiss syndrome in approximately 11,000 necropsies over 20 years at the Boston City Hospital. In these cases the fissures ranged from 0.5 to $3 \mathrm{~cm}$. in length and up to $0.7 \mathrm{~cm}$. in width. Most fissures involved stomach and oesophagus, a few the stomach only, none the oesophagus alone. All lacerations were longitudinal. Six were single, five multiple; 10 occurred in males, one in a female. Five cases had evidence of chronic gastritis. In five cases the lesions were sectioned and appeared as flattened or trench-shaped ulcers based on the submucosa or muscularis. The walls and base showed extravasated red cells, leucocytes, and fibrin and in the older lesions granulation tissue had formed as well.

Kellogg and Blackburn (1954) reported three cases resembling the original description and Hardy (1956) made the diagnosis on gastroscopy in a young man whose haematemesis followed six hours after the vomiting of clear fluid occasioned by 
TABLE I

\begin{tabular}{|c|c|c|c|c|c|c|c|c|c|c|c|}
\hline $\begin{array}{l}\text { Case } \\
\text { No. }\end{array}$ & $\operatorname{sex}$ & Age & $\begin{array}{l}\text { Ante- } \\
\text { cedent } \\
\text { Vomiting }\end{array}$ & $\begin{array}{l}\text { Gastro- } \\
\text { intestinal } \\
\text { Bleeding }\end{array}$ & $\begin{array}{l}\text { Hiatus } \\
\text { Hernia } \\
\text { Demonstrated }\end{array}$ & $\begin{array}{l}\text { Duodenal } \\
\text { Ulcer }\end{array}$ & $\begin{array}{l}\text { Gastric } \\
\text { Ulcer }\end{array}$ & $\begin{array}{l}\text { No. of } \\
\text { Tears }\end{array}$ & $\begin{array}{l}\text { Associated } \\
\text { Conditions }\end{array}$ & Diagnosis & Outcome \\
\hline 1 & $\mathbf{F}$ & 74 & - & + & + & - & - & 1 & Cholelithiasis & Laparotomy & $\begin{array}{l}\text { Well, no further } \\
\text { bleeding }\end{array}$ \\
\hline 2 & $\mathbf{F}$ & 83 & + & + & - & - & + & 1 & & Laparotomy & $\begin{array}{l}\text { Well, no further } \\
\text { bleeding }\end{array}$ \\
\hline 3 & $\mathbf{M}$ & 55 & + & + & + & - & - & 1 & & Gastroscopy & $\begin{array}{l}\text { Well, no further } \\
\text { bleeding }\end{array}$ \\
\hline 4 & $\mathbf{M}$ & 49 & - & + & + & - & - & 1 & Chronic bronchitis & Gastroscopy & $\begin{array}{l}\text { Well, no further } \\
\text { bleeding }\end{array}$ \\
\hline 5 & $\mathbf{M}$ & 74 & + & + & - & - & - & 3 & Cardiac infarction & Necropsy & Died \\
\hline 6 & $\mathbf{M}$ & 66 & - & + & - & - & - & 3 & & Necropsy & Died \\
\hline 7 & $\mathbf{M}$ & 59 & - & + & - & - & - & 2 & & Necropsy & Died \\
\hline 8 & $\mathbf{F}$ & 72 & - & + & + & - & - & 2 & Acute pancreatitis & Necropsy & Died \\
\hline 9 & $\mathbf{F}$ & 75 & - & - & - & - & - & 1 & Status astbmaticus & Necropsy & Died \\
\hline 10 & $\mathbf{F}$ & 84 & - & - & - & + & - & 1 & $\begin{array}{l}\text { Mediastinitis, } \\
\text { (R) empyema }\end{array}$ & Necropsy & Died \\
\hline 11 & $\mathbf{M}$ & 75 & + & - & - & + & - & 3 & $\begin{array}{l}\text { Perforation of } \\
\text { oesophagus, } \\
\text { mediastinitis }\end{array}$ & Necropsy & Died \\
\hline
\end{tabular}

alcoholic excess. Kelley (1958) reported massive haemorrhage following gastroscopy from a tear $2 \mathrm{~cm}$. in length situated $3 \mathrm{~cm}$. below the oesophagogastric junction. He considered that this was a probable case of the Mallory-Weiss syndrome rather than a complication of the examination.

Small and Ellis (1958) reported a case treated surgically; a 44-year-old man vomited during the post-operative period after haemorrhoidectomy, and because bleeding continued laparotomy was performed and revealed a $3 \mathrm{~cm}$. laceration at the cardia. This was sutured and pressure applied by a Sengstaken tube. Bleeding did not recur. Scott and Newton (1958) described a man aged 28 years with an eightyear history of psychogenic vomiting who, at operation for haematemesis, was found to have a single laceration $2.5 \times 0.5 \mathrm{~cm}$. which was sutured successfully. Shuttleworth and Hutt (1958) performed partial gastrectomy for haematemesis in a woman aged 53 with multiple small ulcers in a stomach which was the seat of a chronic gastritis. Post-operatively the patient continued to bleed and a total gastrectomy was performed. Five fissured ulcers were found in the cardia, 7-10 mm. $\times 1 \mathrm{~mm}$., one of which had encroached on the oesophagus.

The present paper describes 11 cases of mucosal tears at the oesophagogastric junction and reports some experimental observations which have a bearing upon the mechanism by which these tears are produced.

\section{CLINICAL FEATURES}

The 11 patients (Table I) described in this paper were all shown to have mucosal tears at the oesophagogastric junction. The diagnosis was established at laparotomy (Cases 1 and 2), by gastroscopy (Cases
3 and 4), and at necropsy in the seven remaining cases. They comprised six men and five women whose ages ranged from 49 to 84 , with a mean of 70 years.

Seven patients presented with haematemesis and/ or melaena, and an eighth was admitted in a shocked state caused by bleeding into the stomach. The other three patients showed no signs of gastrointestinal haemorrhage, although at necropsy some altered blood was found in the stomach in one. Two of these patients developed mediastinitis but in the third the tear apparently caused no disability.

A history of vomiting preceding the haematemesis was obtained in only three of the eight patients with gastrointestinal bleeding and the time interval from the start of vomiting to the first haematemesis varied between half an hour and three hours. One of the three patients without gross gastrointestinal bleeding had vomited, making the overall incidence of antecedent vomiting in the series only four of the total 11 patients. Although an alcoholic debauch precipitated the initial vomiting on one occasion none of our patients were chronic alcoholics. Atrophic changes were noted at gastroscopy in one patient. One patient apparently sustained a mucosal tear at the cardia during a paroxysm of coughing, another when in status asthmaticus, and a third might have sustained the tear during an epileptic convulsion.

A small hiatus hernia was demonstrated radiologically in four patients and three of these gave a history of symptoms suggestive of gastro-oesophageal reflux.

Seven of the 11 patients succumbed, although death in two was not directly attributable to the tear. Of the eight patients who presented with gross haemorrhage, four recovered (two spontaneously and two after operation and suture), three died from 
blood loss, and the other patient died of unrelated disease. Of the three patients who did not have gross bleeding, mediastinitis was the cause of death in two and the third died from an unrelated disease (status asthmaticus). Thus, the mucosal tear at the cardia was the cause of death in five of the 11 patients in the series.

\section{PATHOLOGICAL FINDINGS}

The cardio-oesophageal lesions in those patients who came to necropsy (Table I) all presented similar macroscopic and microscopic features, all of which were comparable with those found in previous descriptions of the ulcers associated with the Mallory-Weiss syndrome. With the exception of the two patients in whom the oesophagus had perforated, the ulcers were superficial and oval or linear, with the long axis in line with the oesophagus, or else pear shaped, with the acute angle directed towards the stomach (Fig. 1). The size of the ulcers varied from $3.5 \times 1.4 \mathrm{~cm}$. to $1.2 \times 0.1 \mathrm{~cm}$. and their number from one to three. The bases of the ulcers were covered by blood or yellow slough; the edges had steep sides with some heaping up of the surrounding mucosa.

The microscopic appearance was that of acutely inflamed ulcers which had penetrated the muscularis mucosa (Fig. 2). The base of the deepest ulcer rested on the oblique muscle, but most were limited to the submucosa. The craters contained a fibrinopurulent exudate with a variable quantity of blood, and the floor was oedematous and acutely inflamed. A certain amount of fibrin had been deposited, but no fibrous tissue appeared to have been formed. A plexus of large, thin-walled blood vessels was usually found in the submucosal tissure surrounding the ulcers (Fig. 2).

The wall of the oesophagus in the upper portion of the tear had perforated in two patients (Fig. 3) and caused death from mediastinitis.

\section{CASE REPORTS}

CASE 1 A woman, aged 74 years, was admitted following a brisk haematemesis. The vomit was bright red blood which welled up effortlessly. For two years she had suffered from mild heartburn occurring 10 minutes after meals and relieved by food and alkalis. Eighteen months before the present admission a barium meal had revealed a small hiatus hernia with free reflux.

On admission her blood pressure was $90 / 55 \mathrm{~mm}$. $\mathrm{Hg}$ and the haemoglobin was $57 \%(8 \cdot 4 \mathrm{~g} . \%)$. Abdominal examination showed an aortic aneurysm, but nothing else of note. A 'ward' barium meal (Cantwell, 1960) revealed gall-stones but no lesion in oesophagus, stomach, or duodenum.
Bleeding continued and three days after admission operation was performed by one of us (B.G.P.). The whole gut was full of blood. There was a saccular aneurysm extending from the upper abdominal aorta to both iliac arteries and the presence of gall-stones was confirmed. The stomach and duodenum felt normal and gastrotomy was performed. There was much fresh blood in the fundus and on the posterior wall of the cardia there was a narrow elongated fissure approximately $2 \times 0.2 \mathrm{~cm}$. which was seen to be bleeding freely. Two catgut sutures applied to the fissure controlled the bleeding. Recovery was uneventful.

CASE 2 A woman, aged 83 years, complained of intermittent pain in the left hypochondrium of three years' duration. The pain was unrelated to meals and had never been accompanied by vomiting. On the day of admission she vomited a small amount of clear fluid followed half an hour later by a large haematemesis. She continued to bleed and her condition deteriorated in spite of blood transfusion.

At laparotomy by one of us (R.E.W.), 24 hours after admission, the stomach was dilated with blood and clot but there was no external evidence of a gastric or duodenal ulcer. A wide gastrotomy was performed. A small scar was found on the lesser curvature but this was not the source of bleeding. There was a tear about $2 \mathrm{~cm}$. long on the anterior wall of the stomach immediately below the oesophagogastric mucosal junction. This tear was sutured with catgut and the patient made an uneventful recovery.

CASE 3 A bricklayer, aged 55 years, had suffered from intermittent heartburn after meals and on bending for 10 years. On the day of admission, after several pints of beer, he vomited twice. Feeling better again, he had a further drink which precipitated further vomiting, this time productive of blood.

On admission to hospital one hour later he was rather pale but showed no signs of shock. No physical abnormality was found. The haemoglobin was $78 \%(11.5 \mathrm{~g} . \%)$ and stool occult blood tests were strongly positive during the first week in hospital. Barium studies three days after admission to hospital revealed no radiological abnormality of the oesophagus, stomach, or duodenum. Gastroscopy seven days after the patient's coming into hospital revealed an atrophic gastric mucosa in which mucosal blood vessels could be seen. The antrum appeared normal and showed active peristalsis. At the cardia, however, a shallow linear ulcer with a greyish white base and reddened margins extended from the anterior wall of the stomach across the mucosal junction into the oesophagus (Fig. 4).

Recovery was entirely uneventful and he was discharged from hospital after 14 days, quite free from symptoms. A further barium meal two months after discharge revealed a small hiatus hernia.

CASE 4 A 49-year-old van driver had suffered from bronchitis for several years. On the day before admission to hospital, after a bout of coughing, a clot of blood appeared in the mouth and shortly afterwards he passed 
FIG. 1. Case 5. Necropsy specimen showing three tears at the cardia. All extend across the mucosal junction and penetrate to the submucosa.

FIG. 2. Histological section of the largest tear in Fig. 1 $(\times 35)$. This has been converted into an acutely inflamed ulcer. Note the proximity of the tear to the blood vessels of the submucosa.

FIG. 3. Case 11. Stomach and oesophagus at necropsy showing three tears (marked with arrows), one of which has perforated the oesophagus.

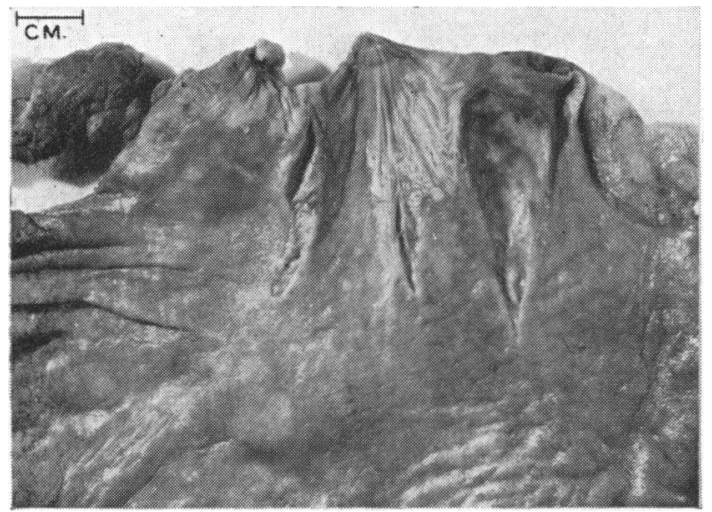

FIG. 1

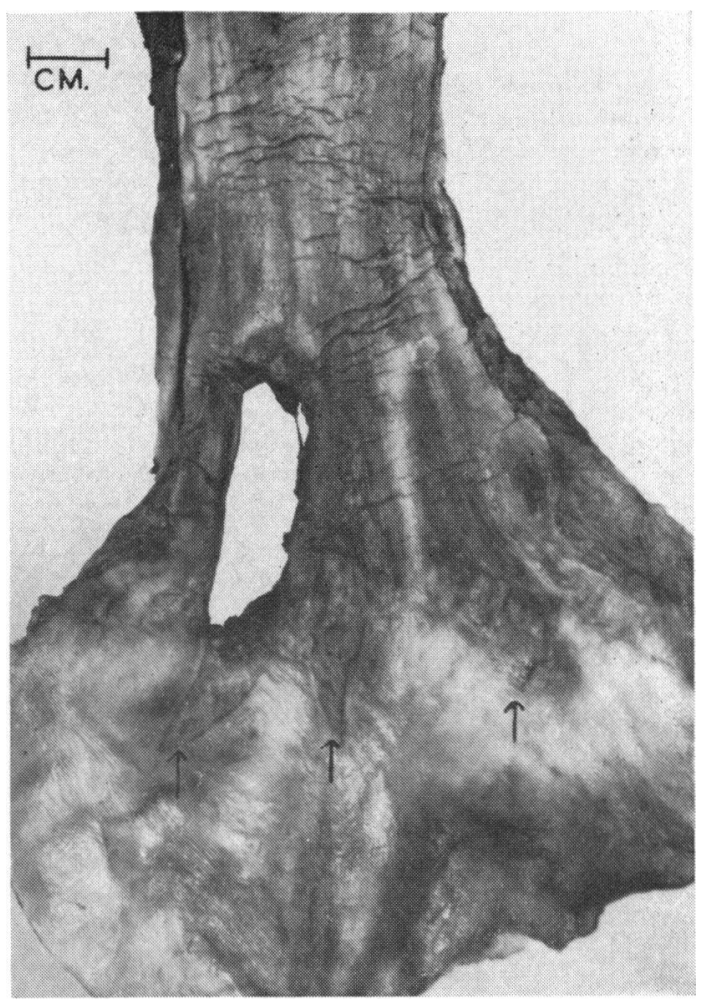

FIG. 3

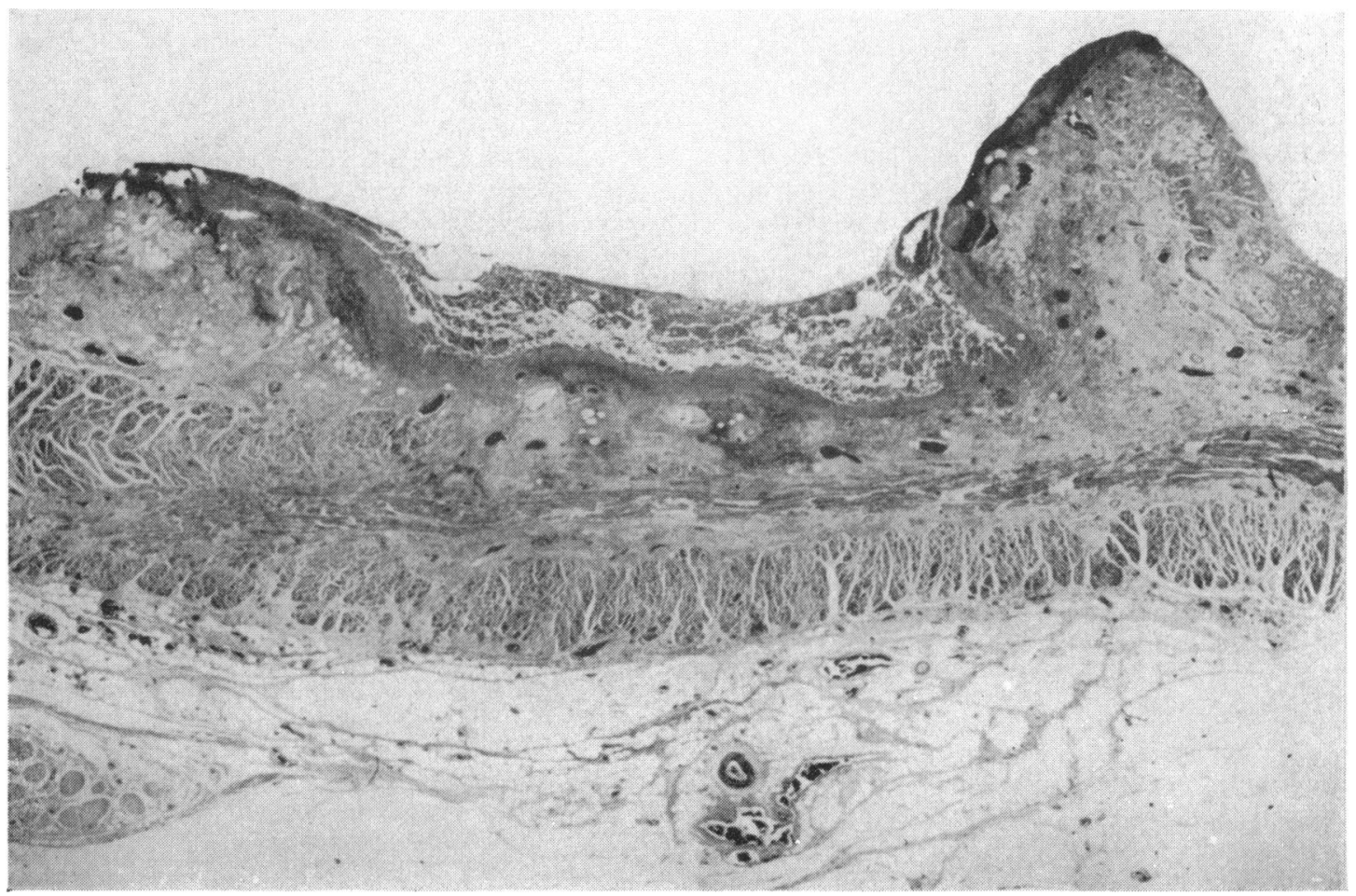

FIG. 2 

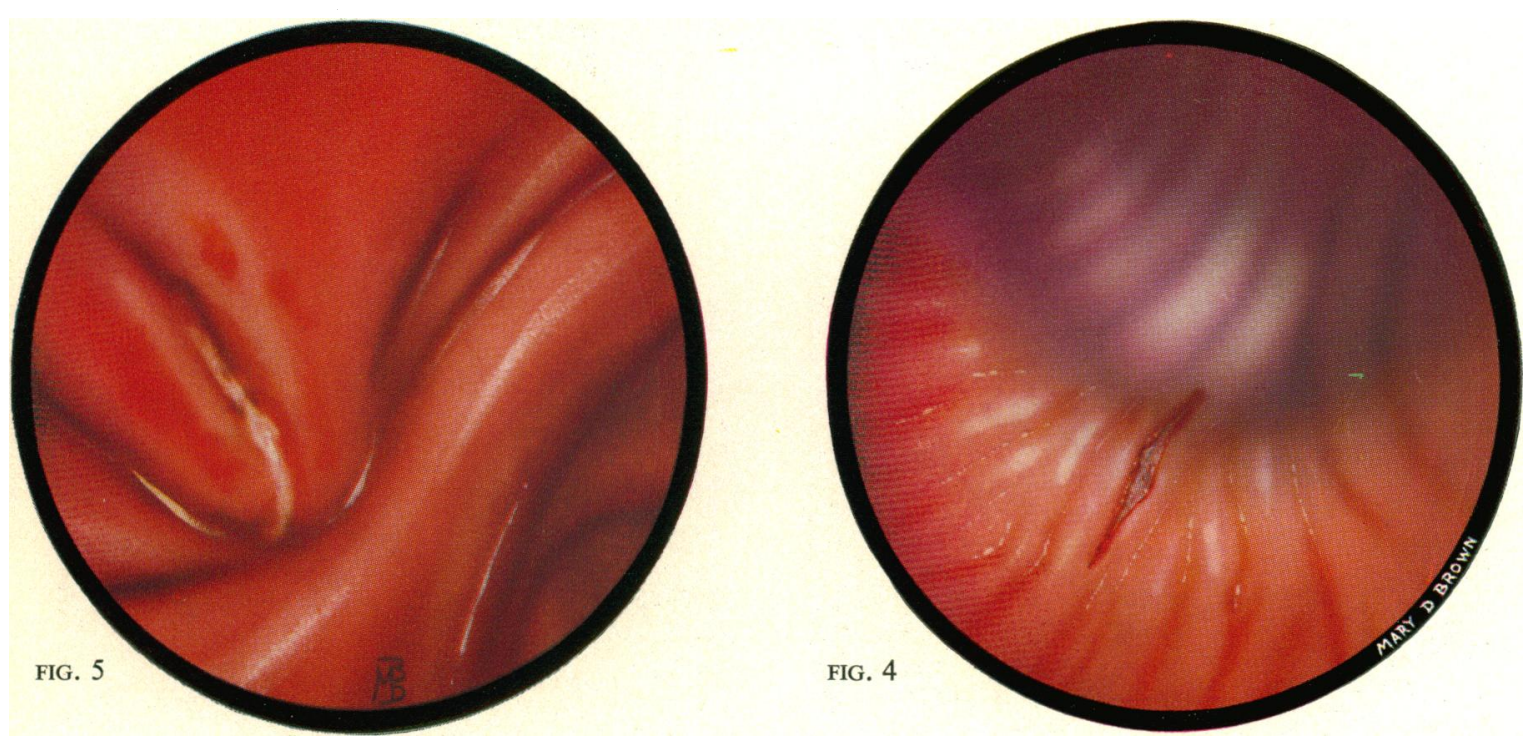

FIGS. 4 and 5. Gastroscopic appearances in Cases 3 and 4 showing a healing tear extending across the oesophagogastric junction (Fig. 4) and a superficial linear ulcer at the cardia with some blood clot adherent to its central portion (Fig. 5).

a melaena stool. On the day of admission he fainted at work and passed several more melaena stools.

Examination on admission revealed pallor but no other abnormality. He was transfused with 3 pints of blood. A ward barium meal showed a small hiatus hernia but no other abnormality. Gastroscopy two days after admission revealed a linear ulcer on a reddened mucosal fold on the anterior aspect of the cardia (Fig. 5). This appeared to extend into the oesophagus and old blood clot was adherent to its central portion. The gastric mucosa looked slightly atrophic but no other abnormality was found. Bleeding ceased spontaneously and he was discharged 10 days later.

CASE 5 A man, aged 74 years, was admitted with haematemesis. Two weeks before admission he experienced sudden chest pain when walking uphill. This pain subsided with rest, but recurred frequently until the day of admission when he developed severe precordial pain and vomited twice. The material vomited on the second occasion contained a little blood. Shortly after this he had a haematemesis of approximately 2 pints.

On admission his general condition was poor, he was grossly anaemic and electrocardiography showed the changes of anterior myocardial infarction. Blood transfusion was started but he died suddenly 36 hours after admission following another haematemesis.

Post-mortem examination showed severe coronary atheroma with a recent small anterior myocardial infarct. Blood was found in the stomach, small and large bowel. Three fissured ulcers were present at the cardia of the stomach, the largest measuring $3.5 \times 1.5 \mathrm{~cm}$. (Fig. 1). The microscopic appearance was that of an acutely inflamed ulcer penetrating to the muscularis mucosa (Fig. 2). No other lesion was found in the gastrointestinal tract.

CASE 6 A man, aged 66 years, who had suffered from epilepsy for 10 years, was admitted unconscious; he was severely shocked and died before reaching the ward. He had never suffered from dyspepsia and there had been no recent vomiting or overt gastrointestinal bleeding.

At necropsy the stomach and upper jejunum were distended by several pints of blood. There were three fissured ulcers in the cardiac region measuring $2.5 \times 0.75$ $\mathrm{cm}$., $1.5 \times 0.5 \mathrm{~cm}$., and $1.0 \times 0.5 \mathrm{~cm}$. respectively. One involved stomach and oesophagus while the other two were confined to the stomach. Fresh clot was adherent to the floor of one ulcer, suggesting that bleeding had stopped before death. The gastric mucosa was normal and no other lesion was found in the gastrointestinal tract. Old infarcts were present in the brain associated with cerebral arteriosclerosis and these probably accounted for the epilepsy.

Histological sections of the oesophagogastric lesions showed a breach of the mucosa exposing the vascular submucosa but not extending deeper into the wall. Laminated blood clot was adherent to the floor of one ulcer (Fig. 6). There was very little associated cellular infiltration of the ulcers and most of the cells were polymorphs, indicating the acute nature of the lesion. The gastric mucosa was healthy with no evidence of gastritis.

CASE 7 A man, aged 59 years, was admitted with a history of having passed several small black motions the same day. There had been no haematemesis, previous dyspepsia, or vomiting. On admission his general condition was good with a haemoglobin level of $83 \%$ 


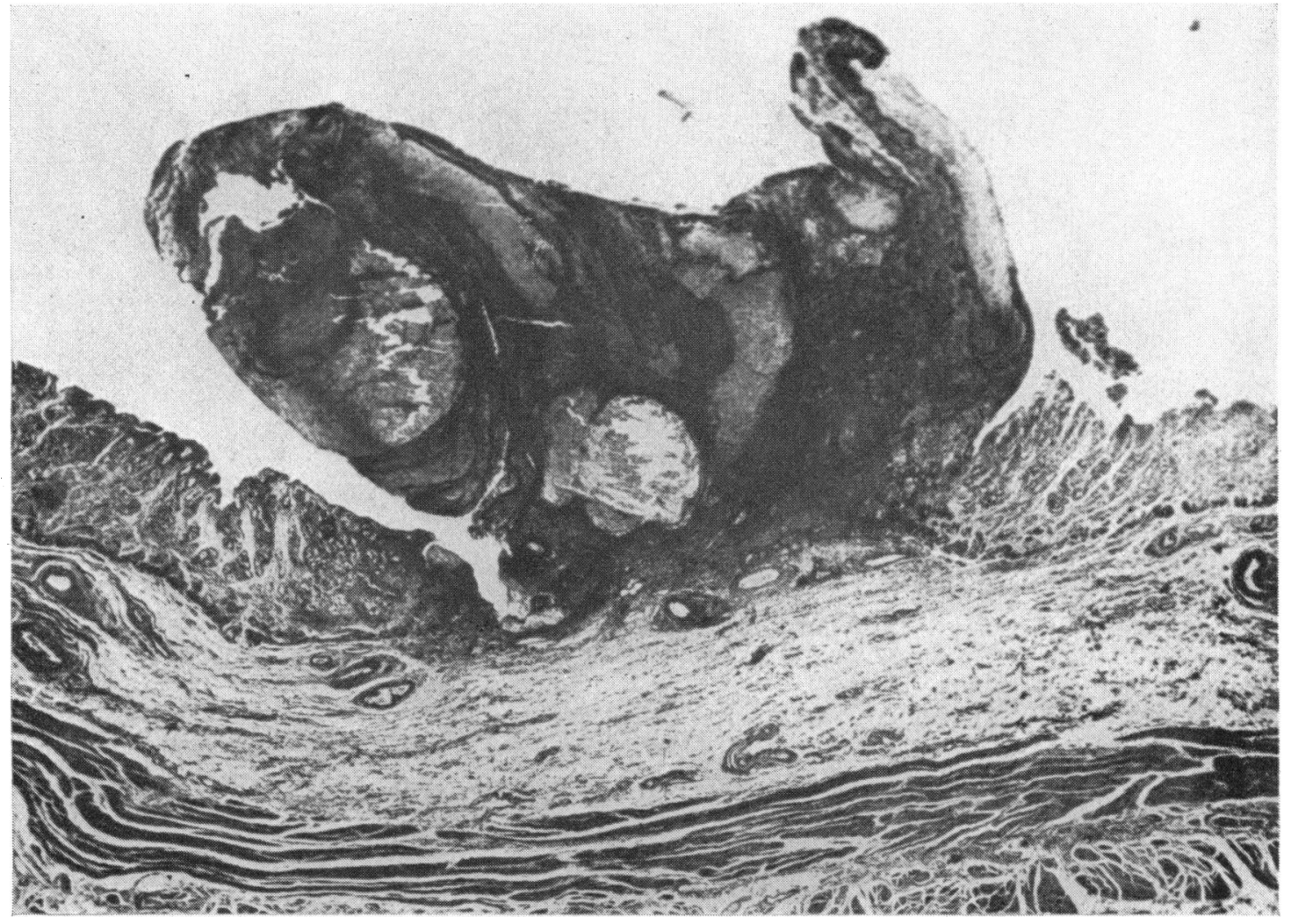

FIG. 6. Case 6. Histological section of mucosal tear showing adherent laminated blood clot. There is little surrounding cellular infiltration.

$(12.3$ g. $\%)$. Recurrent haematemeses during the next two days necessitated blood transfusion and led to the decision to operate. However, before he could be transferred to the operating theatre he died suddenly after a massive haematemesis.

At necropsy the stomach and upper intestine contained large amounts of blood. The sources of bleeding were two linear mucosal tears in the cardiac region. These measured $2.75 \times 1.25 \mathrm{~cm}$. and $1.0 \times 0.75 \mathrm{~cm}$. The first lay across the oesophagogastric junction and the second was confined to the stomach (Fig. 7). No other gastrointestinal source of bleeding was found.

CASE 8 A woman, aged 72 years, was admitted in a confused state having had a haematemesis. She had vomited after meals for some time but the last such episode had been weeks previously. A barium meal showed a small hiatus hernia but no other abnormality in the oesophagus, stomach, or duodenum. Her condition gradually deteriorated and she died one week later without further bleeding.

Necropsy showed that the cause of death was cerebral softening due to generalized arteriosclerosis. There was resolving acute pancreatitis and above the oesophagogastric junction were two healing tears. A small hiatus hernia was present but no other abnormality was found in the gastrointestinal tract.

CASE 9 A woman, aged 75 years, who had suffered from asthma for 10 years, was admitted in status asthmaticus. Her condition deteriorated and she died five days later. There was no vomiting before death.

Necropsy showed a small mucosal tear, $1.5 \times 0.7 \mathrm{~cm}$., lying across the oesophagogastric mucosal junction. There was no evidence of bleeding and no other lesion was present in the gastrointestinal tract.

CASE 10 A woman, aged 84 years, died following a fracture of the neck of the femur. There was no history of vomiting or haematemesis before death. At necropsy, a tear measuring $4.6 \times 1.0 \mathrm{~cm}$. was found, mainly in the stomach but extending across the oesophagogastric mucosal junction (Fig. 8). This had perforated at its upper end causing mediastinitis and a right-sided empyema. A chronic duodenal ulcer was also found. No evidence of haemorrhage was discovered.

CASE 11 A man, aged 75 years, had suffered from a chronic duodenal ulcer for $\mathbf{4 0}$ years, and often vomited. 


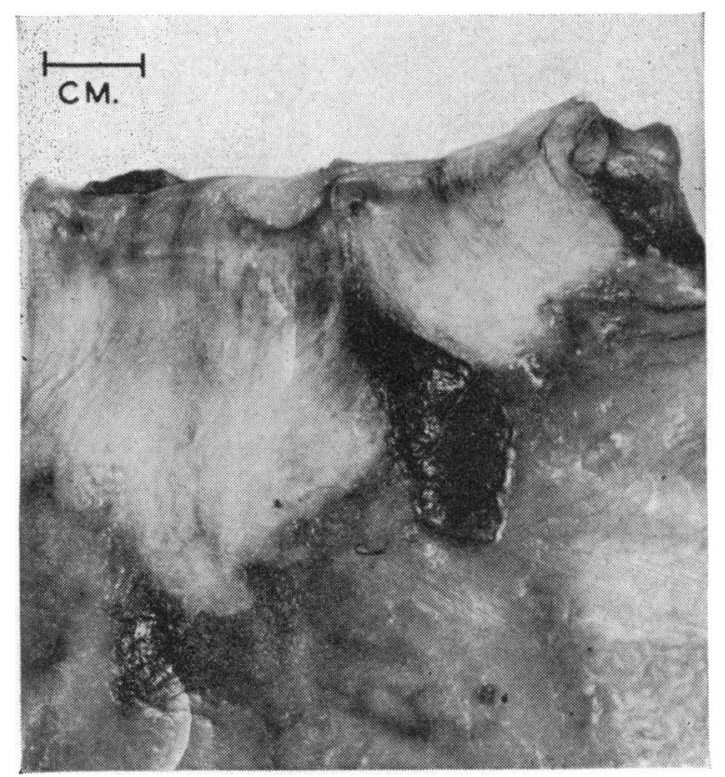

FIG. 7. Oesophagogastric junction in Case 5 showing two tears.

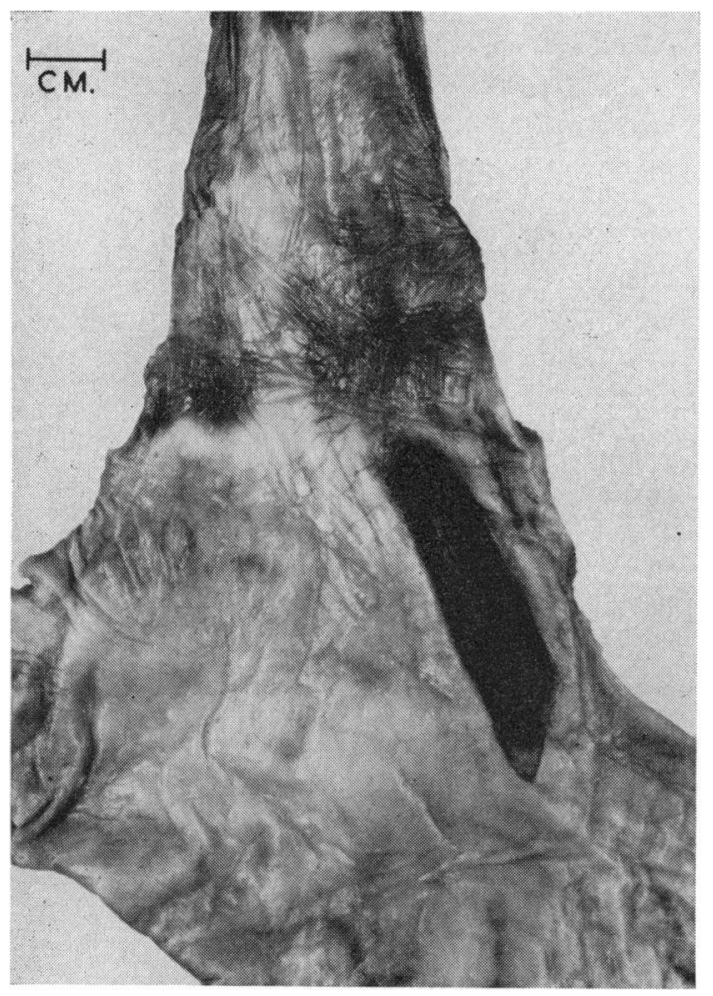

FIG. 8. Oesophagogastric junction in Case 10. The oesophagus had perforated at the upper end of the tear causing mediastinitis.
He was admitted complaining of sudden severe generalized abdominal pain accompanied by frequent vomiting, but no haematemesis. The pain later localized in the left hypochondrium and lower left thorax. His condition rapidly deteriorated and he died 15 hours later.

At necropsy, three linear tears were found, measuring $5 \times 0.8 \mathrm{~cm}$., $2.5 \times 0.7 \mathrm{~cm}$., and $1.6 \times 0.7 \mathrm{~cm}$. All crossed the oesophagogastric mucosal junction and the largest had perforated the wall of the oesophagus (Fig. 3). A posterior mediastinitis and bilateral pleural effusions were found. The stomach contained altered blood and a chronic duodenal ulcer was present.

\section{EXPERIMENTAL OBSERVATIONS ON THE MECHANISM OF MUCOSAL TEARS AT THE CARDIA}

To investigate the mechanism of the production of tears at the oesophagogastric junction and to obtain some measure of the magnitude of the forces involved, experiments were made in the cadaver within 36 hours of death. These were designed to determine the intragastric pressure required to produce mucosal tears of the stomach in situ. For comparative purposes measurements of intragastric and intraoesophageal pressure during straining and retching were made in five normal subjects.

NECROPSY STUDIES Through a window in the thoracic cage the oesophagus was clamped at the level of the arch of the aorta taking care not to disturb the anatomy of the diaphragm or its attachments. By reflecting the left lung forward the lower oesophagus could be inspected continuously throughout the subsequent distention. Through an incision in the anterior abdominal wall the stomach was transected at the antrum and the cardiac region inspected to exclude antemortem mucosal tears. A wide-bore brass cannula, with a side arm to which was attached a mercury manometer, was then tied into the transected proximal portion of the stomach and through this the organ was distended with air. Intragastric pressure was increased further by manual pressure on the anterior wall of the already distended stomach until a predetermined level was reached. This was maintained momentarily and then released. The cannula was removed and the cardia inspected for tears. The results obtained are shown in Table II, where it will be seen that the

\section{TABLE II}

INTRAGASTRIC PRESSURE REQUIRED TO PRODUCE MUCOSAL TEARS AT THE CARDIA IN THE CADAVER

\begin{tabular}{ccc}
$\begin{array}{l}\text { Intragastric } \\
\text { Pressure }(\mathrm{mm} . \mathrm{Hg})\end{array}$ & No. of Cadavers & $\begin{array}{l}\text { No. in which Tears } \\
\text { were Produced }\end{array}$ \\
\hline 90 & 5 & 0 \\
100 & 5 & 1 \\
110 & 5 & 0 \\
120 & 6 & 0 \\
130 & 5 & 2 \\
140 & 5 & 3 \\
150 & 6 & 6
\end{tabular}

frequency with which mucosal tears were produced was directly related to the pressure applied; a tear was 


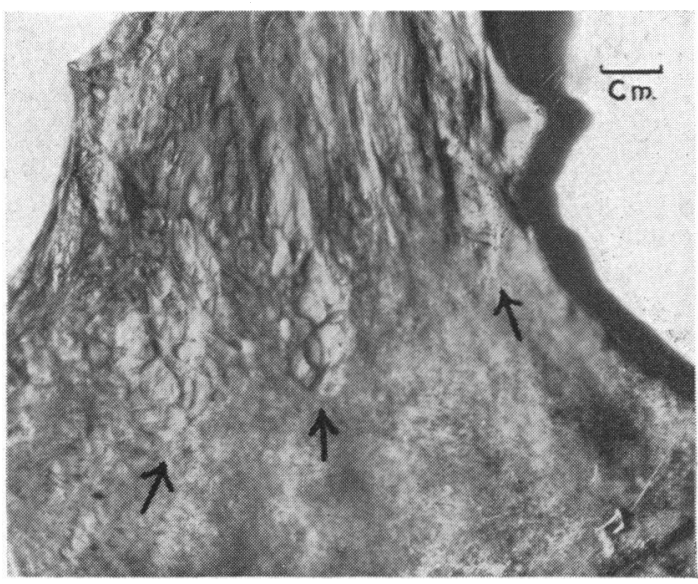

FIG. 9. Three tears (marked by arrows) produced by distending the stomach in situ at necropsy. These bear a close resemblance in position and shape to antemortem lacerations. Submucosal vessels are visible in the bases of the tears.

produced in one cadaver with an intragastric pressure of $100 \mathrm{~mm}$. $\mathrm{Hg}$ and at $150 \mathrm{~mm} . \mathrm{Hg}$ tears were produced in each of six cadavers. The tears were longitudinal in position and were confined to the oesophagogastric junction (Fig. 9), closely resembling those described in the preceding case histories. Histological section of these experimental tears of course showed no vital reaction but often revealed the submucosal vessels to be exposed (Fig. 10).

STUDIES DURING STRAINING AND RETCHING Intragastric pressure was recorded from the stomach just below the cardia, through a fine, water-filled polyethylene tube attached to a capacitance manometer outside the body, in five healthy staff and students. With the subject fasting and lying on the left side pressures were measured during straining and during retching induced by touching the back of the throat with a wooden spatula. The level of intragastric pressure reached varied from 120 to 160 $\mathrm{mm}$. $\mathrm{Hg}$ and this was usually sustained for several seconds. Transient increases of pressure of up to 200 $\mathrm{mm}$. $\mathrm{Hg}$ were found.

Intra-oesophageal pressure rose to levels of 35 to 50 $\mathrm{mm}$. $\mathrm{Hg}$ in the five subjects, indicating that during straining intrathoracic pressure is considerably less than intragastric pressure.

\section{DISCUSSION}

Mallory and Weiss ascribed the mucosal lesions they noted to laceration caused by 'pressure changes in the stomach during a disturbed mechanism of vomiting'. Although this view has in general been

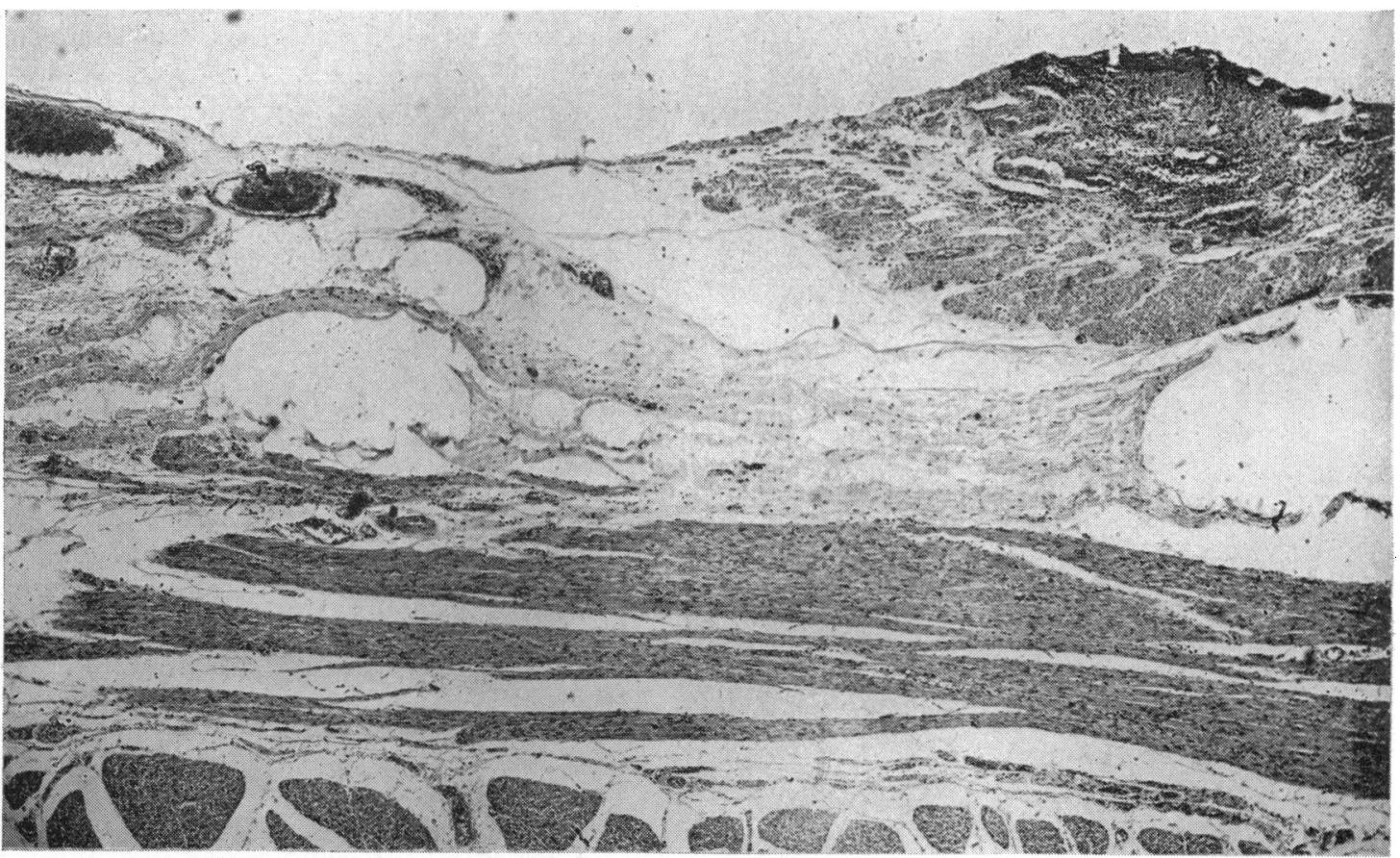

FIG. 10. Histological section of tear in Fig. $9(\times 35)$. There is no vital reaction. Note the proximity of the tear to the large vessels in the submucosa. 
accepted, Bruce and Dudley (1959) have suggested that the mucosal lesions start as linear acute ulcers rather than as tears in the mucosa. These they would regard as a variety of proximal peptic ulcer of the type described by Dieulafoy (1898) and by Gilchrist and Chun (1954). We believe that these lesions begin as tears which are subsequently converted into shallow ulcers before undergoing complete healing. This view is based on the fissured shape of the lesions and the fact that similar tears can be produced by distending the stomach of the cadaver.

Tearing of the gastric mucosa will presumably depend upon the degree of stretching of the stomach, which will be related to the pressure gradient across the wall rather than the absolute level of intragastric pressure. During straining, retching, and vomiting the increase in intragastric pressure is largely due to increase in intra-abdominal tension brought about by contraction of the abdominal wall muscles and the diaphragm. Hence the degree of stretching of the stomach wall would be much less than that produced by gastric distension in the cadaver in spite of the fact that we recorded comparable levels of intragastric pressure. However, mucosal tears are found almost invariably at the oesophagogastric junction and seem to occur more frequently in patients with hiatus hernia. In fact a hiatus hernia was demonstrated in four of our 11 patients. In hiatus hernia the intraluminal pressure in the herniated portion of the stomach corresponds with that in the subdiaphragmatic portion of the organ rather than with the general level of intrathoracic pressure (Atkinson, Edwards, Honour, and Rowlands, 1957). Under these circumstances, the pressure gradient across the gut wall at the oesophagogastric junction will be high because intrathoracic pressure during straining, retching, and vomiting is much lower than intra-abdominal pressure. The intraoesophageal pressures of up to $50 \mathrm{~mm}$. $\mathrm{Hg}$ which we recorded from normal subjects during retching and straining give an approximate measure of intrathoracic pressure. Hence, if the oesophagogastric junction lies in the thorax the pressure gradient across its wall will be of the order of $100 \mathrm{~mm}$. $\mathrm{Hg}$ or more, and stretching in this region will be greater than in the wall of the intra-abdominal portion of the stomach.

Not in every patient who sustains a mucosal tear at the cardia can a hiatus hernia subsequently be demonstrated. As the diagnosis of small hiatus hernias is often difficult both at radiological examination and at necropsy, it may be that all our patients did in fact suffer from this abnormality. An alternative explanation would be that the sharp descent of the diaphragm during vomiting does in fact cause the cardia to lie temporarily in the thorax, and it is at this time that the tears may be sustained. Nauta (1956) has demonstrated considerable movement of the oesophagogastric junction in relationship to the diaphragmatic hiatus in the intact dog and such mobility could provide an explanation for the causation and localization of mucosal tears at the cardia in the human. Fleischner (1956) believes that mucosal tears at the cardia occur when the oesophagogastric junction is in the thorax and thus that they are produced by a mechanism analogous to that by which oesophageal rupture is caused (Mackler, 1952). Indeed in two of our cases (10 and 11), with typical tears, the oesophagus was perforated.

An additional factor which requires consideration is the resistance of the mucosa. Gastric mucosal atrophy was present in five of the 11 cases described by Decker et al. (1953) in Shuttleworth's and Hutt's patient and in at least one patient of the present series (Case 2). The aetiological significance of this is difficult to assess as the condition is so common (Joske, Finckh, and Wood, 1955), but mucosal atrophy occurring with age may well predispose to mucosal tears, and the fact that most of our patients were advanced in years would be in keeping with this view. Chronic alcoholism, which features so prominently in the original description of the syndrome, was not present in any of our patients.

Mucosal tears at the oesophagogastric junction are generally regarded as a rare cause of gastrointestinal bleeding and receive little, if any, mention in most of the reports of large series of patients with upper gastrointestinal haemorrhage. However, Chalmers, Zamcheck, Curtins, and White (1952) mention three cases of the Mallory-Weiss syndrome in a series of 101 patients, and Palmer (1952) suspected this diagnosis on clinical grounds in seven of 121 patients admitted with gastrointestinal haemorrhage, although visual confirmation was not obtained. Our own experience suggests that mucosal tears account for a significant proportion of upper gastrointestinal bleeding episodes; after our attention had been drawn to this disorder by Case 1 , no fewer than four (Cases 2, 3, 4, and 5) of the next 73 consecutive patients admitted with haematemesis and/or melaena were found to have mucosal tears in the region of the cardia. It is generally agreed that no cause can be found for upper gastrointestinal bleeding in a considerable proportion of patients admitted to hospital on this account; this proportion amounted to $26 \%$ of 325 patients in Schiff's series (1947) and $21 \%$ of 1,910 patients reported by Avery Jones (1956). Although the diagnosis in these patients has been presumed to be acute ulceration, it seems probable that a number may in fact have suffered from mucosal tears at the cardia. 
Emesis followed within a few hours by haematemesis is the classical clinical presentation. Vomiting from almost any cause may be responsible for the initial episode and alcoholic excess (Case 2), pancreatitis (Case 8), peptic ulcer, which was present in three of our cases $(2,10$, and 11), uraemia (Kellogg and Blackburn, 1954), and vomiting of pregnancy have all been incriminated. However, in no fewer than seven of our patients no history of vomiting preceding the gastrointestinal bleeding could be obtained. Violent contraction of the diaphragm and abdominal muscles during paroxysms of coughing, status asthmaticus, and an epileptic convulsion might have been the cause of the mucosal tears in three of our patients.

It seems probable that not every mucosal tear is followed by gastrointestinal haemorrhage. This was illustrated by Cases 9 and 10 in our series in which mucosal tears were found at necropsy in patients who had never had overt bleeding. If no haemorrhage occurs these tears will almost certainly pass unnoticed unless the lesion involves the full thickness of the wall causing mediastinitis (as in patients 10 and 11).

The diagnosis of mucosal tears at the cardia presents many difficulties even when the clinician is alert to the possibility. These lesions cannot be demonstrated radiologically, they are in a region which is difficult to inspect endoscopically, and will be missed at laparotomy unless an extensive gastrotomy be performed. Furthermore, they may be mistaken for artefacts by the endoscopist, by the surgeon at operation, or by the pathologist at necropsy. Bleeding from these tears may cease spontaneously, and if the diagnosis is suspected on clinical grounds endoscopy may provide confirmation if performed within a week of bleeding.

Occasionally bleeding continues and laparotomy may have to be undertaken as in Cases 1 and 2 of this series. Here again the diagnosis is largely dependent upon the surgeon bearing in mind the possibility of mucosal tears; in the absence of an obvious source of bleeding the cardia should be inspected through a gastrotomy opening. Should such an inspection be neglected and an empirical 'blind' gastrectomy be performed, bleeding may well continue. If a mucosal tear is found at operation carefully placed sutures will usually control the bleeding (Scott and Newton, 1958) as in Cases 1 and 2.

\section{SUMMARY}

Eleven patients with mucosal tears at the oesophagogastric junction are reported, the diagnosis being established by gastroscopy in two, at laparotomy in two, and at necropsy in the remaining seven.
Gastrointestinal bleeding was the presenting feature in eight and two of them required laparotomy for control of haemorrhage. Of the three remaining patients, two suffered from mediastinitis and the third had no relevant symptoms. It is suggested that these mucosal tears account for a significant proportion of the $20-25 \%$ of haematemeses in which no cause can be discovered.

Similar mucosal tears could be produced at the cardia in the cadaver by distending the stomach to a pressure of 100-150 mm. Hg.

Four of our patients suffered from small hiatus hernias and it is suggested that these mucosal tears occur when the cardia is displaced into the thorax and the pressure gradient across the wall is high.

We are indebted to the physicians and surgeons under whose care some of these patients were admitted to hospital, to Miss Mary D. Brown, of the Department of Surgery, The General Infirmary at Leeds, for the paintings of the gastroscopic appearances in Cases 3 and 4, and to Mr. F. P. Hainsworth, F.R.P.S., A.I.B.P., of St. James's Hospital, for the photographs.

\section{REFERENCES}

Atkinson, M., Edwards, D. A. W., Honour, A. J., and Rowlands, E. N. (1957). The oesophagogastric sphincter in hiatus hernia. Lancet, 2, 1138-1142.

Bruce, J., and Dudley, H. A. F. (1959). Gastrectomy for massive gastrointestinal haemorrhage of unknown cause. Ibid., 2 , 992-994.

Cantwell, D. F. (1960). Ward barium meal examination in acute gastro-intestinal haemorrhage. Clin. Radiol., 11, 60-64.

Chalmers, T. C., Zamcheck, N., Curtins, G. W., and White, F. W. (1952). Fatal gastrointestinal hemorrhage: clinico-pathologic correlations in 101 patients. Amer. J. clin. Path., 22, 634-645.

Decker, J. P., Zamcheck, N., and Mallory, G. K. (1953). MalloryWeiss syndrome. Hemorrhage from gastroesophageal lacerations at the cardiac orifice of the stomach. New Engl. J. Med., 249, 957-963.

Dieulafoy, G. (1898). Exulceratio simplex: L'intervention chirurgicale dans les hématémèses foudroyantes consécutives a l'exulcération simple de l'estomac. Bull. Acad. Méd. (Paris), 3 ser., 39, $49-84$.

Fleischner, F. G. (1956). Hiatal hernia complex. Hiatal hernia, peptic esophagitis, Mallory-Weiss syndrome, hemorrhage and anemia, and marginal esophagogastric ulcer. J. Amer. med. Ass., 162, 183-191.

Gilchrist, R. K., and Chun, N. (1954). Severe hemorrhage in presumed peptic ulcer. Surgical treatment in the absence of demonstrable lesion. A.M.A. Arch. Surg., 69, 366-377.

Hardy, J. T. (1956). Mallory-Weiss Syndrome. Report of case diagnosed by gastroscopy. Gastroenterology, 30, 681-685.

Jones, F. Avery (1956). Hematemesis and melena with special reference to causation and to the factors influencing the mortality from bleeding peptic ulcers. Ibid., 30, 166-190.

Joske, R. A., Finckh, E. S., and Wood, I. J. (1955). Gastric biopsy. A study of 1,000 consecutive successful gastric biopsies. Quart. J. Med., 24 (n.s.), 269-294.

Kelley, M. L., Jr. (1958). Massive hemorrhage following gastroscopy; probable example of Mallory-Weiss syndrome. Amer. J. dig. Dis., n.s. 3, 454-463.

Kellogg, R. O., and Blackburn, N. P. (1954). The Mallory-Weiss syndrome. J. Maine med. Ass., 45, 318-320.

Mackler, S. A. (1952). Spontaneous rupture of the esophagus: an experimental and clinical study. Surg. Gynec. Obstet., 95, 345-356. 
Mallory, G. K., and Weiss, S. (1929). Hemorrhages from lacerations of the cardiac orifice of the stomach due to vomiting. Amer. J. med. Sci., 178, 506-515.

Nauta, J. (1956). The closing mechanism between the oesophagus and the stomach. Gastroenterologia (Basel), 86, 219-232.

Palmer, E. D. (1952). Observations on the vigorous diagnostic approach to severe upper gastrointestinal hemorrhage. Ann. intern. Med., 36, 1484-1491.

Schiff, L. (1947). In Signs and Symptoms, ed. C. M. MacBryde, pp. 344-359. Lippincott, Philadelphia.
Scott, N. M. Jr., and Newton, D. E. (1958). Mallory-Weiss syndrome-report of a case treated surgically. Amer. J. dig. Dis., n.s. 3, 464-468.

Shuttleworth, K. E. D., and Hutt, M. S. R. (1958). Mallory-Weiss syndrome-a case with recovery after total gastrectomy. Brit. J. Surg., 46, 1-3.

Small, A. B., and Ellis, P. R. (1958). Laceration of the distal esophagus due to vomiting (the Mallory-Weiss syndrome). Report of a case with massive hemorrhage and recovery after repair of the laceration. New Engl. J. Med., 258, 285-286. 